\title{
An Assessment of the Effectiveness of Productivity Improvement Programs (Pips) of the Regional Tripartite Wages and Productivity Board - Region X (RTWPB-X): A Case Study of Selected SMEs
}

\author{
Odette Leh C. Valdehueza-Caragos ${ }^{1}$ and Kerwin Salvador P. Caragos ${ }^{2}$
}

\begin{abstract}
This research aimed to assess the effectiveness the status of implementation of the SMEs after the introduction of RTWPB-X PIP; the number of SMEs that had improved from Year 2014-2016 in terms of total productivity (TP), employment generation, product and service diversification and market expansion, productivity-related awards and recognitions, HR capacity-building, human and labor relations and welfare programs, systems, technology, and green programs; and formulation of an action plan to improve RTWPB-X PIPs. In the evaluation of impact, this study utilized the theory of change where hypotheses were frequently written as causal "if-then" propositions in a development hypothesis description. The result of the study bared that all SMEs implemented and accomplished $100 \%$ of their PIPs from Year 2014-2016; had increased their total productivity; had a positive growth of employment; had human and labor relations and welfare programs and benefits in place; and had improved systems, technology, and green programs. The action plan in this study formulated an eight-step road map to help create more effective training materials. The study concluded that connecting training to the SMEs business results definitely helped to prove the fact that RTWPB-X training program intervention produced desired results as intended and met its intended impact. The study recommended that to give quality and sufficient training, the training programs should be divided among staff so that there would be focus on how it will be handled and its accountability. A mapping should be done. Thus, creation of a database per training program with categorization whether the SME trained should be in the refreshers, beginners, intermediate, or advance training is highly suggested. Also, the study recommended the overall entrepreneurial ecosystem needs to be nurtured through long-term education strategy to build the next generation of entrepreneurs; simplified and streamlined registration processes for business start-ups; supporting women entrepreneurs to foster women's empowerment; stronger crisis resilience for the SMEs by holistic support mechanisms; and effective strategies for health and wellness for productive societies.
\end{abstract}

Keywords- Productivity Improvement Program, Total Productivity, Theory of Change, Small Medium Enterprises, Regional Tripartite Wages and Productivity Board-Region X.

Odette Leh C. Valdehueza-Caragos, Xavier University - Ateneo de Cagayan

Kerwin Salvador P. Caragos, Capitol University

\section{INTRODUCTION}

The Regional Tripartite Wages and Productivity Board Region X (RTWPB-X) is an attached agency of the Department of Labor and Employment (DOLE). It is a policy making body on productivity, incomes, and wages authorized through Wage Rationalization Act of 1989 (RA 6727) and Productivity Incentives Act of 1990 (RA 6971) that fix minimum wages at the regional, provincial and/or industry levels and advocate productivity improvement and gainsharing schemes, particularly among micro, small and medium enterprises (MSMEs).

This research was performed to assess the effectiveness of RTWPB-X PIPs in selected SMEs that aimed to answer the following questions: Was there an implementation of the SMEs after the introduction of RTWPB-X PIP?; How many SMEs had improved from Year 2014-2016 in terms of total productivity (TP), employment generation, product and service diversification and market expansion, productivity-related awards and recognitions, HR capacity-building, human and labor relations and welfare programs, systems, technology, and green programs?

This study utilized the theory of change in the evaluation of impact. Numerous propositions were laid out in a series described as strategy's "theory of change" (USAID). The mission was not to accept or reject program theories but to improve them (Leeuw and Vaessen, 2009).A development hypothesis postulated what will happen if a particular intervention will be commenced or an amalgamation of some segment that were vital for getting on a specific development outcome were established. Hypotheses were frequently written as causal "if-then" propositions in a development hypothesis description.

The causal "if-then" propositions of this study were the following:

If SMEs receive ISTIV-PAP training program, THEN SMEs participants experience specific changes in their skills, knowledge, or attitudes.

If SMEs participants change their skills, knowledge, or attitudes, Then they will change their performance and customary practice in their work area. 
IF enough SMEs participants change their performance and practice, Then the program may have a larger impact in their work area.

\section{REVIEW OF RELATED LITERATURE AND STUDIES}

The W.K.Kellogg Foundation Logic Model Development Guide (2006) emphasized that understanding and applying logic model tools served to augment the practitioner's influence in the areas of development, design, execution, investigation, and knowledge generation. The course of developing the model is a mindful process that forms a clear comprehension of the encounters in the future, the time in which to achieve the mark, and the resources available. Moreover, it helped retain a balanced focus on the macro and micro perspectives.

Harris (2005) expounded that a logic model can be used to give details on how an outcome will be generated once the precondition has been pinpointed through the TOC process. McCawley (1997) also explained that the logic model aimed to measure the effectiveness of a given project or program in changing the undesired condition to have the intended outcome. Wilder Research conducted in 2009 explained the link between program or project components and outcomes. The following elements were generally included, namely:

- Inputs: any materials or resources utilized by the program to support its undertakings (e.g., money, manpower, machines, supplies, facilities)

- Activities: any treatments or services supplied by the program

- Outputs: expanse of activity supplied that is expressed in quantifiable expressions such as number of hours of service provided, number of people assisted, number of classes trained, amount of information and educational materials disseminated

- Outcomes: According to the program theory, any attributes of the participants as a result of change that occurred after the participants obtained the program.

A study by Loveridge (2011) on "Theories of change: monitoring and evaluation (M\&E) capacity development in the Government of Tanzania" articulated that the theories of change method sought to draw to the surface the context, mechanisms and outcomes to underscore how change was anticipated to occur. It also identified if the theories championed were parallel to those in use, whether partial, chaotic, or contradictory.

Another study made by Breuer, Lee, De Silva, and Lund (2016) made a systematic review of the interventions utilizing theory of change (ToC) in the crafting of the design and impact assessment. The study showed that $79 \%$ used ToC in the evaluation of the intervention and $29 \%$ in the development of the intervention from 62 papers reviewed. However, the paper lacked details on the development, use of the intervention design, and assessment of the ToC although its use was widespread in the public health literature. It was worthy to note the significance to have a transparent reporting of the ToC process (i.e. checklist of reporting) and outputs in order to improve understanding of the advantages and benefits of using it.
Hill and Thies (2010) utilized program theory and logic model to evaluate and assess a comprehensive community initiative. The study found out that program planning with huge community-wide collaborations were hard to develop, may not benefit the program stakeholders, and may harm more ways in which many of the strategies and outcomes overlap. Another study made by Mahamed (2013) aimed to produce a results-based monitoring and evaluation system on Developing an M\&E System for the Ceasefire Gang Violence program in Hanover Park, Cape Town. The evaluation has responded to the questions about the program theory of the Ceasefire gang violence program, if the theory and a customized framework was possible, and the appropriate application of a result-based M\&E system. Records and documents of the program were scrutinized and interviews were conducted as a response to the first evaluation question. The information obtained from the research was used to develop the process theory of the program and determine its impact. The summary of the program theory developed stated that gang violence problem will be reduced if the Ceasefire Program intervenes and interrupts gang violence at the street level, and if the program provided identified clients with behavioral modification training and referred them to social services then the program educated the community to change their violent norms and values. As a response to the question on the second evaluation, a literature review and evaluation findings were conducted on approaches that dealt with gang violence problems in communities. The studied literature has shown that there were four common approaches that were used to address the problem of gang violence in communities, namely: intervention/disengagement, prevention, multiple approach models and suppression/law enforcement. The dissertation expounded that the Ceasefire program used the multiple approach models in solving gang violence problems in Hanover Park and found to be reasonable in decreasing gang violence issues. The third evaluation question intended to find out the causes of gang violence in the Cape Flats communities and the planned activities the Ceasefire program management made to suit it locally. Thus, the following recommendations were laid out after due deliberations of the information in the local context:

- To develop a prevention outreach program on gang violence for the community through schools to discourage the youth in the community to involve in gang violence or join gangs.

- To employ rehabilitated program by establishing a peer-to-peer outreach program to assist the individual gang members to leave their life as a gang and avert them from getting involved in gang violence.

- To arrange for a Safe House facility for the participants of the program who would want to abandon their gang life outside of the Hanover Park community.

- To offer a service to the program participants on tattoo removal that could help them further to give up their gang life.

- The response to the fourth evaluation question is the development of a results-based M \& E system for the 
Ceasefire Program comprised of implementation and outcomes monitoring frameworks (Ibid).

\section{RESEARCH MethodolOGY}

Firstly, according to levels of investigation, this study was a descriptive research that systematically described the situation factually and accurately. Secondly, according to statistical content, this study was a quantitative-qualitative research that study facts and causes through the use of both quantitative and qualitative research. Thirdly, according to choice of answers to problems, this was an evaluation research that identified all possible sources of action and specify which was most advantageous in terms of the process and the result of the program delivery. Fourthly, according to purpose, this study was also a directive research that provided action or direction of the study. And, lastly, according to goal, this study was an action research that developed new approaches and solved problems that have direct application in the setting in which the research was conducted without any assumption about the general applications (Prado, et al., 2011).

In this research, the Business Diagnosis Form (for the "before intervention analysis), Action Plans (for the activities to be done by the SME to improve their productivity) of the ISTIV-PAP Training and the Evaluation Form (for the empirical evidence of the productivity improvement) were used to assess the effectiveness of the RTWPB-X Programs to the Company Beneficiaries.

\section{DISCUSSION OF RESUlTS}

The economic activities of each enterprise were different from the other, namely: dressed chicken, wine-making, domestic shipping, toll processing that includes dressing, cutting, blasting, deboning, marination and distribution of chicken, feed production, coco sugar production, selling of lechon manok, pork liempo, liempo de lechon and other Filipino delicacies.
The subsequent step was analyzing the input of the Logic Model, i.e., the resources put into the project in terms of time, financial resources and facilities. This step was important in terms of understanding the impact, as the impact was looked at as the outcomes considering the inputs. The input as identified in this research was the RTWPB-X PIP, particularly the ISTIV-PAP Training.

Activities or procedures were the thorough projects and action steps taken in aid of the strategies. They were the link between the short-term outcomes and the identified strategies and were akin to customary objectives in terms of being quantifiable. In other words, the activities were specifically designed to produce the short-term outcomes identified in the logic model (Hill and Thies, 2010). The activities of the MSMEs were listed through action planning.

The result of the project were those tangible activities or actions as a consequence of the input, i.e. the investments made in terms of finance and human resources. The outputs should not be mistaken for the outcomes and impact, but should rather be looked upon as the activities from the project, which lead to the outcomes. The outcomes were then examined considering the objectives of the project. The logic model from an evaluation perspective, the objectives must be translated into more specific and precise statements of how we can measure these objectives in order to measure the impact (McCawley, 1999). Setting up indicators of (the desired) change was crucial in measuring the impact, and was a necessary step between the objectives and the impact (Birkmose, 2012). 
TABLE I: IMPLEMENTATION AFTER THE INTRODUCTION OF RTWPB-X PIPS ON TOTAL NUMBER OF PIPS IMPLEMENTED

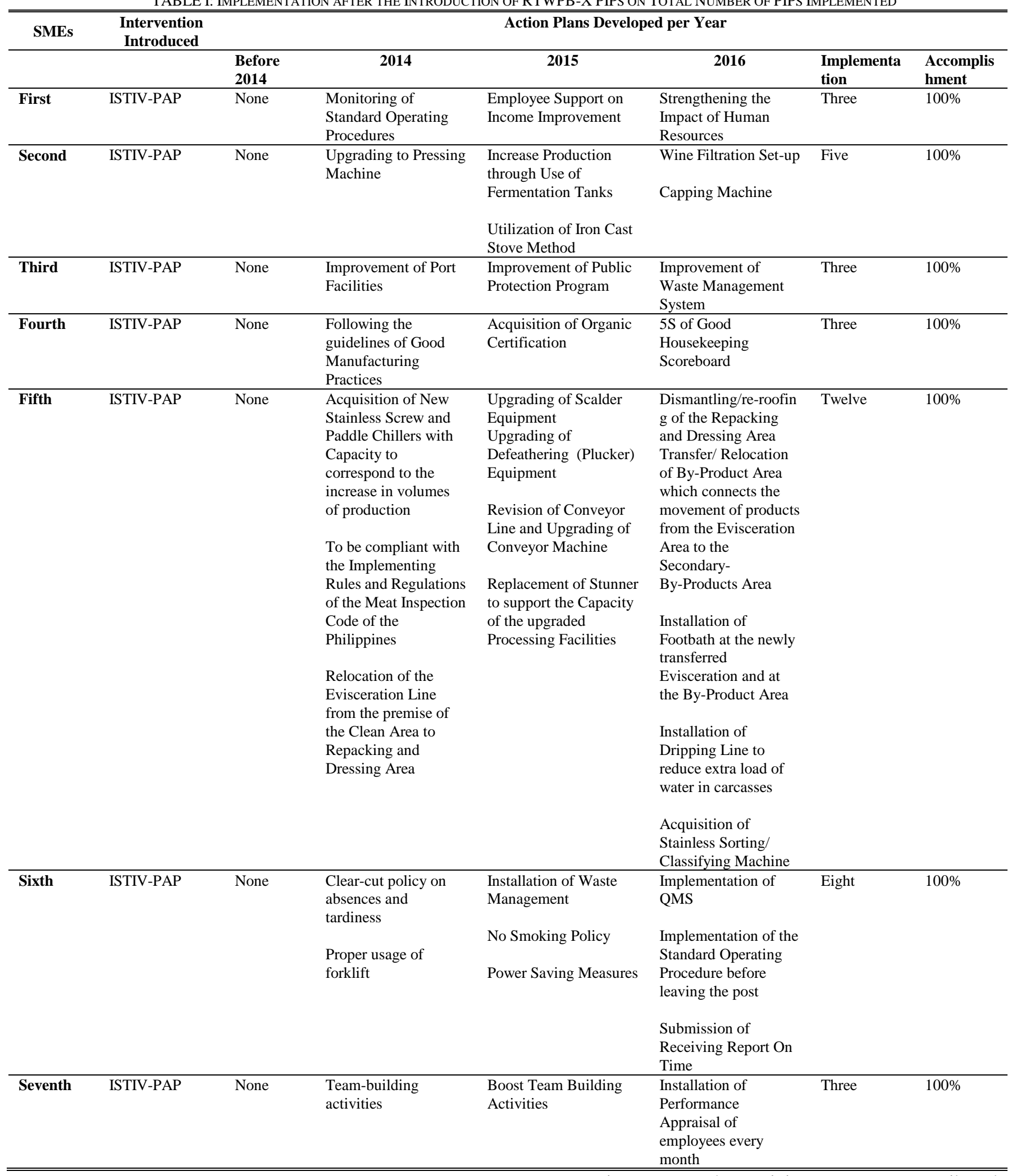

\section{CONCLUSION}

Connecting training to the SMEs business results definitely helped to prove the fact that RTWPB-X training program intervention was warranted and produced desired results as intended. It can be concluded that based on the data, for three consecutive years, the training program contributed to year-over-year improvements. It can also be concluded that the intervention met its intended impact. Does training played a significant role in the work arena? Unquestionably. But it could not solve every problem, and its effectiveness depends on how it was designed, developed, and implemented (Dalto, 2014).

Overall, SMEs faced numerous constraints to further growth 
and productivity, including credit constraints, cumbersome registration procedures and strict regulatory environments, and other challenges related to an economic playing field that was not leveled between large and small firms. SMEs, especially start-ups, have lower probabilities of survival than larger firms, leading to high rates of market entry and exit across nearly all economic sectors. To go beyond survival and actually compete, SMEs will need to undergo successful business transformation in various dimensions of their operations - spanning enhanced entrepreneurial skill, innovation in process and product development, more successful collaboration across SMEs and with larger firms, and improved crisis resilience among other factors (Mendoza et al, 2014).

\section{ACKNOWLEDGMENT}

The researchers were profusely thankful to Prof. Richardson T. Cua, Dr. Isaias S. Sealza, Dr. Catherine Roween C. Almaden, and Prof. Marichu M. Obedencio for the recommendations and improvement of this research; To Zenaida B. Chan-Valdehueza, Stephanie Rosalind P. Caragos, Katrina Dominique V. Caragos, Kristina Danica V. Caragos, Kara Daniella V. Caragos, Atty. Ma. Vergel B. Walag, the XU Graduate School staff - Ma'am Joy M. Mañigo and Janice Mary Balane, Bartolome A. Grejalde, Jr., for the numerous support.

\section{REFERENCES}

[1] Boundless. (2016). "Total Factor Productivity." Boundless Economics Boundless. Retrieved on June 19, 2017 from https://www.boundless.com/economics/textbooks/boundless-economic s-textbook/inputs-to-production-labor-natural-

resources-and-technology-14/capital-productivity-and-technology-8 2/total-factor-productivity-316-12413/

[2] Breuer, E, Lee, L, De Silva, M, \& Lund, C. (2016). Using theory of change to design and evaluate public health interventions: a systematic review. Implement Sci, 11 (1). p. 63. ISSN 1748-5908 DOI: 10.1186/s13012-016-0422-6. Retrieved January 8, 2017 from http://researchonline.lshtm.ac.uk/2549323/1/13012_2016_ Article_422.pdf

[3] Dalto, Jeffrey (2014). How to Create an Effective Training Program: 8 Steps to Success. Convergence Training. Retrieved June 19, 2017 from https://www.convergencetraining.com/blog/how-to-create-an-effectivetraining-program-8-steps-to-success

[4] Evaluation Ethics (2009). Wilder Research. Retrieved April 10, 2017 from

http://www.evaluatod.org/assets/resources/evaluation-guides/evaluatio $n$ ethics -2-09.pdf

[5] Grimes, Cliff F. Supervisors Guide to Productivity Improvement Accel-Team. Retrieved January 6, 2017 from www.accel-team.com/_pdf/atpdf_08_extract.pdf

[6] Harris, S. (2016). What is Theory of Change? Retrieved January 6, 2017 from https://www.theoryofchange.org/what-is-theory-of-change/

[7] Leeuw, Frans and Vaessen, J. (2009). Impact evaluation and development. NONIE and World Bank, Washington

[8] Loveridge, D. L. (2011). Theories of change: monitoring and evaluation capacity development in the government of Tanzania. Doctorate, Centre of Program Evaluation, Melbourne Graduate School of Education, the University of Melbourne. Retrieved January 6, 2017 from http://cat.lib.unimelb.edu.au/record=b4049652

[9] McCawley, P. (1999). The Logic Model. US: University of Idaho Extension. Retrieved January 6, 2017 from http://www.d.umn.edu/ kgilbert/educ5165-731/Readings/The\%20Logi c\%20Model.pdf

[10] Mendoza, Ronald and Melchor, Monica (2014). SMEs in the Philippines: Going beyond survival. Retrieved January 6, 2017 from https://www.rappler.com/thought-leaders/74674-smes-philippines-asia n-institute-management

[11] Prado, Nenita I, Penaso, Anthony M, Cimene, Francis Thaise A., Aves, Luvismin S., and Simbulan, Sol G. (2014). Research Methods. Cagayan de Oro City, Philippines: CMU-IMDC

[12] Productivity Incentives Act (1990). Republic Act 6971. Retrieved January 6, 2017 from www.nwpc.dole.gov.ph/.../ra6971PRODUCTIVITY\%20INCENTIV E\%20S\%20ACT

[13] Sullivan, John. (2011). Increasing Employee Productivity: The Strategic Role That HR Essentially Ignores. Retrieved June 10, 2017 from https://www.eremedia.com/ere/increasing-employee-productivity-the-st rategic-role-that-hr-essentially-ignores/

[14] Wage Rationalization Act (1989). Republic Act 6727. Retrieved April 21 2017 from www.nwpc.dole.gov.ph/pages/download/.../IRR\%20on\%20RA\%20 6727MWF.pdf

[15] W.K. Kellogg Foundation Logic Model Development Guide. (2013). Retrieved May 13, 2017 from https://www.healthra.org/download-resource/?resource-url=/wp-conten t/uploads/2013/08/LM_definitions_WKK.pdf 